\title{
Clinical Pharmacy Services in Canadian Emergency Departments: A National Survey
}

\author{
Richard Wanbon, Catherine Lyder, Eric Villeneuve, Stephen Shalansky, Leslie Manuel, \\ and Melanie Harding
}

\begin{abstract}
Background: Providing clinical pharmacy services in emergency departments (EDs) is important because adverse drug events commonly occur before, during, and after ED encounters. Survey studies in the United States have indicated a relatively low presence of clinical pharmacy services in the ED setting, but a descriptive survey specific to Canada has not yet been performed.

Objectives: To describe the current status of pharmacy services in Canadian EDs and potential barriers to implementing pharmacy services in this setting.
\end{abstract}

Methods: All Canadian hospitals with an ED and at least 50 acute care beds were contacted to identify the presence of dedicated ED pharmacy services (defined as at least 0.5 full-time equivalent [FTE] position). Three different electronic surveys were then distributed by e-mail to ED pharmacy team members (if available), pharmacy managers (at hospitals without an ED pharmacy team), and ED managers (all hospitals). The surveys were completed between July and September 2013.

Results: Of the 243 hospitals identified, 95 (39\%) had at least 0.5 FTE clinical pharmacy services in the ED (based on initial telephone screening). Of the $60 \mathrm{ED}$ pharmacy teams that responded to the survey, 56 had pharmacists (27 of which also had ED pharmacy technicians) and 4 had pharmacy technicians (without pharmacists). Forty-four (79\%) of the 56 ED pharmacist services had been established within the preceding 10 years. Order clarification, troubleshooting, medication reconciliation, and assessment of renal dosing were the services most commonly provided. The large majority of pharmacy managers and ED managers identified the need for ED pharmacy services where such services do not yet exist. Inadequate funding, competing priorities, and lack of training were the most commonly reported barriers to providing this service.

Conclusions: Although the establishment of ward-based pharmacy services in Canadian EDs has increased over the past 10 years, lack of funding and a lack of ED training for pharmacists were reported as significant barriers to the expansion of this role in most hospitals.

Keywords: emergency department, pharmacist, Canada, survey, pharmacy, technician

\section{RÉSUMÉ}

Contexte : Offrir des services de pharmacie clinique dans les services des urgences est important, car des événements indésirables liés aux médicaments se produisent fréquemment avant, pendant et après y avoir séjourné. Des études par sondage réalisées aux États-Unis font état d'une présence relativement faible des services de pharmacie clinique dans les services des urgences. Malheureusement, aucune enquête descriptive n'a été menée au Canada à ce jour.

Objectifs : Dresser le portrait actuel des services de pharmacie au sein des services des urgences du Canada et présenter les obstacles potentiels à l'établissement de services de pharmacie dans ce milieu.

Méthodes : On a communiqué avec l'ensemble des hôpitaux canadiens disposant d'un service des urgences et d'au moins 50 lits de soins de courte durée afin de savoir s'ils profitaient de services de pharmacie consacrés au service des urgences (soit au moins 0,5 d'un poste équivalent temps plein). Trois différents sondages électroniques ont ensuite été envoyés par courriel : un aux membres du personnel de pharmacie affectés aux services des urgences (le cas échéant); un aux gestionnaires de pharmacie (des hôpitaux sans équipe de pharmacie au service des urgences); et un aux gestionnaires des services des urgences (de tous les hôpitaux). Les sondages ont été remplis entre juillet et septembre 2013.

Résultats : Des 243 hôpitaux recensés, 95 (39\%) avaient au moins 0,5 d'un poste équivalent temps plein pour la prestation de services de pharmacie clinique au service des urgences (résultat établi au moyen d'une présélection téléphonique). Parmi les 60 équipes de pharmacie affectées au service des urgences ayant répondu au sondage, 56 disposaient de pharmaciens (et parmi celles-ci, 27 comptaient aussi sur des techniciens en pharmacie) et 4 étaient composées exclusivement de techniciens en pharmacie. Quarante-quatre (79\%) des 56 équipes comprenant des pharmaciens avaient été mises en place au cours des dix dernières années. La clarification des ordonnances, le dépannage, l'établissement de bilans comparatifs des médicaments et l'évaluation de l'ajustement posologique chez les insuffisants rénaux représentaient les services les plus souvent offerts. La vaste majorité des gestionnaires de pharmacie et des gestionnaires des services des urgences ont souligné la nécessité d'avoir des services de pharmacie au service des urgences dans les établissements où il n'y en avait pas encore. Le manque de financement, le nombre foisonnant de priorités et l'insuffisance de formation représentaient les éléments faisant le plus souvent obstacle à l'instauration de ce service selon les répondants.

Conclusions : Bien que la mise en place de services de pharmacie clinique consacrés aux services des urgences ait augmenté au Canada durant les 
Can J Hosp Pharm. 2015;68(3):191-201 dix dernières années, le manque de financement et l'insuffisance de formation des pharmaciens pour le travail au service des urgences ont été présentés comme étant d'importants obstacles à l'accroissement de ce rôle dans la plupart des hôpitaux.

Mots clés : service des urgences, pharmacien, Canada, sondage, pharmacie, technicien

\section{INTRODUCTION}

$\mathrm{P}$ harmacists have become an integral part of the health care team in many patient care areas in the hospital setting. Clinical pharmacy services reduce adverse drug events (ADEs) and readmissions, improve medication adherence and appropriateness, and shorten hospital stays with no worsening of clinical outcomes. ${ }^{1-5}$ The following clinical pharmacy services have been associated with reduced mortality rates: drug-use evaluation, provision of in-service education, adverse drug reaction management, drug protocol management, participation on the cardiopulmonary resuscitation team, participation on patient rounds, and preparation of admission drug histories. ${ }^{1}$ Emergency department (ED) pharmacists may provide all of these services and may perform additional roles, including participation in trauma responses, procedural sedation, and intubating patients. ${ }^{6-14}$ ED clinical pharmacy services are cost-effective ${ }^{15,16}$ and are recognized by ED teams as integral to improving the quality of care to patients. ${ }^{17}$ The role of the ED pharmacist has been previously described. ${ }^{16,18-32}$

ADEs account for $12 \%-28 \%$ of $\mathrm{ED}$ visits and $24 \%$ of hospital admissions. ${ }^{23,33-36}$ They are associated with longer hospital stays and greater costs to the health care system. ${ }^{34,37-42}$ Numerous factors make the ED a high-risk environment for medication errors: large patient volumes, high patient - health care provider ratios, high turnover of nursing staff, diversity of clinical presentations, large number of distractions, frequent use of verbal medication orders, and use of high-risk medications. ${ }^{22}$ The majority of ADEs that occur within 2 weeks after discharge from the $\mathrm{ED}$ are preventable, and most patients experiencing an $\mathrm{ADE}$ return for a repeat $\mathrm{ED}$ visit. ${ }^{43}$

Over one-third of drug-related ED presentations identified by pharmacists are missed by emergency physicians..$^{23,24}$ Pharmacy services that include medication review, patient counselling, and telephone follow-up have been associated with an absolute reduction by 10 percentage points in preventable ADEs at 30 days after discharge, and this pharmacy service is highly valued by other ED care providers. ${ }^{44,45}$ The ED is likely a very good location for pharmacists to identify and resolve preventable ADEs.

The provision of appropriate clinical pharmacy services in the ED may increase compliance with several guidelines and standards developed for the care of ED patients. As of 2015, Accreditation Canada's Qmentum program will expect EDs to initiate medication reconciliation for 2 groups of patients: (1) those with a decision to admit and (2) those without a decision to admit who meet the criteria of a risk-based, health care organization-defined selection process. ${ }^{46}$ The CSHP 2015 initiative of the Canadian Society of Hospital Pharmacists includes objectives relevant to clinical pharmacy practice in the $\mathrm{ED}$ (i.e., those that address medication reconciliation, ED medication order review within $24 \mathrm{~h}$, care of patients in ambulatory clinics, and emergency preparedness). ${ }^{47}$

Pharmacists have provided services to EDs since the $1970 \mathrm{~s},{ }^{25}$ but surveys in the United States over the past 20 years have indicated that relatively few hospitals (between $1 \%$ and $14.9 \%$ ) have dedicated ED pharmacy services. ${ }^{15,25,48-50}$ According to the Hospital Pharmacy in Canada 2011/2012 Report, 57\% of EDs in Canadian hospitals with 50 or more inpatient beds had pharmacists assigned, but the extent of ED coverage and services was not defined. ${ }^{51}$ The US Institute of Medicine identified the relatively low presence of clinical pharmacy services in EDs as a limitation to building safe medication practices in this setting. ${ }^{52}$

The objectives of this study were to identify the proportion of Canadian EDs with dedicated ED pharmacy services (defined as at least 0.5 full-time equivalent [FTE] position), to describe current ED pharmacy practices in Canada, and to describe potential barriers to the provision of $\mathrm{ED}$ pharmacy services. It is anticipated that the results of this study will help pharmacists and managers to understand the potential scope of pharmacy practice in Canadian EDs.

\section{METHODS}

Canadian hospitals with at least 50 acute care beds and an ED were identified using provincial and territorial ministry of health reports. Internet searches and personal communications with specific hospitals and health care centres were used to identify hospitals in regions where such reports were not available (i.e., Manitoba, Yukon, Northwest Territories, and Nunavut). A minimum of 50 acute care beds was selected on the basis of feasibility and a previous survey that did not identify any ED pharmacy services in 89 US hospitals with fewer than 50 acute care beds..$^{50}$ This threshold is also consistent with that used in the Hospital Pharmacy in Canada 2011/2012 Survey. ${ }^{51}$ There were no exclusion criteria. 
Hospitals that met the inclusion criteria were reached by telephone to obtain contact information for a hospital-specific ED manager and a hospital-specific pharmacy manager, clinical coordinator, or director. ED charge nurses were asked whether the hospital had an ED pharmacist or pharmacy technician position of at least $0.5 \mathrm{FTE}$. The response to this question was verified by telephone with a pharmacist from each hospital's dispensary.

Both English and French versions of 3 different electronic surveys were developed by 7 Canadian pharmacists ( 5 of whom were ED pharmacists in Canada) using FluidSurveys version 4.0 (2011) software (FluidSurveys, Ottawa, Ontario):

- The survey for ED pharmacy staff was forwarded to ED pharmacists (or ED pharmacy technicians at hospitals with no ED pharmacist) working at least $0.5 \mathrm{FTE}$ in the ED. This survey took about 5-15 min to complete, with survey questions describing the role and extent (hours and days per week) of clinical pharmacy services provided in the ED. Only one response to this survey was collected from each hospital.

- The survey for pharmacy managers was forwarded to pharmacy managers, clinical coordinators, or directors (hereafter referred to collectively as "pharmacy managers") of hospitals with less than 0.5 FTE pharmacist services assigned to the ED. This survey took about $5 \mathrm{~min}$ to complete, with the survey questions assessing potential barriers to initiating $\mathrm{ED}$ pharmacist services. Only one response to this survey was collected from each hospital.

- The survey for ED managers was forwarded to ED managers at all hospitals. This survey took about $5 \mathrm{~min}$ to complete, with survey questions assessing the current, or potential, value that ED pharmacy services have, or would have, to ED staff. Only one response to this survey was collected from each hospital.
The surveys were tested for face validity, but no validated survey process on this topic was available for the research group to utilize. Approval for the study was obtained from the Health Research Ethics Board of Island Health. One survey invitation and 2 reminders, all containing consent information, were sent by e-mail to each potential participant. Consent was implied by responding to the survey. Responses to the survey as a whole and to individual survey questions were voluntary, and no compensation or other incentive was offered. Survey responses were collected between July and September 2013. Descriptive statistics were used to analyze the data.

\section{RESULTS}

This study identified 243 hospitals in Canada with at least 50 acute care beds and an ED. More than half of the hospitals were located in Ontario and Quebec (Table 1). After the preliminary telephone survey, different surveys were distributed to 141 hospital pharmacy managers, $243 \mathrm{ED}$ managers, and $95 \mathrm{ED}$ pharmacy staff, with variable response rates (Figure 1).

The majority of ED pharmacy staff respondents reported 100 or more ED visits per day, and 28 (47\%) of $60 \mathrm{ED}$ pharmacy staff respondents reported 20 or more admissions from the ED each day.

Of the 59 Canadian hospitals with more than 350 acute care beds, 48 (81\%) reported having dedicated ED pharmacy services. Only 5 (9\%) of the 56 smaller hospitals (50-100 acute care beds) reported having dedicated ED pharmacy services.

\section{Survey of ED Pharmacy Team}

There were up to 95 hospitals with ED pharmacy services in Canada (90 with ED pharmacists and 5 with ED pharmacy

Table 1. Regional Distribution of Hospitals Identified

\begin{tabular}{lccc} 
Province or Territory & $\begin{array}{c}\text { No. of Hospitals with } \mathbf{5 0} \\
\text { Acute Care Beds and ED }\end{array}$ & $\begin{array}{c}\text { No. (\%) of Hospitals with } \\
\text { ED Pharmacy Services* }\end{array}$ \\
\hline Yukon & 1 & 0 & $(0)$ \\
Northwest Territories & 1 & 0 & $(0)$ \\
Nunavut & 0 & 0 & $(0)$ \\
British Columbia & 31 & 11 & $(35)$ \\
Alberta & 17 & 4 & $(24)$ \\
Saskatchewan & 12 & 3 & $(25)$ \\
Manitoba & 10 & 7 & $(70)$ \\
Ontario & 76 & 32 & $(42)$ \\
Quebec & 67 & 37 & $(55)$ \\
Newfoundland and Labrador & 7 & 0 & $(0)$ \\
New Brunswick & 9 & 5 & $(56)$ \\
Nova Scotia & 10 & 3 & $(30)$ \\
Prince Edward Island & 2 & 0 & $(0)$ \\
\hline Total & 243 & 102 & $(42)$ \\
\hline ED = emergency department. & & & \\
*Based on telephone screening with front-line staff in the ED and the pharmacy department, &
\end{tabular}




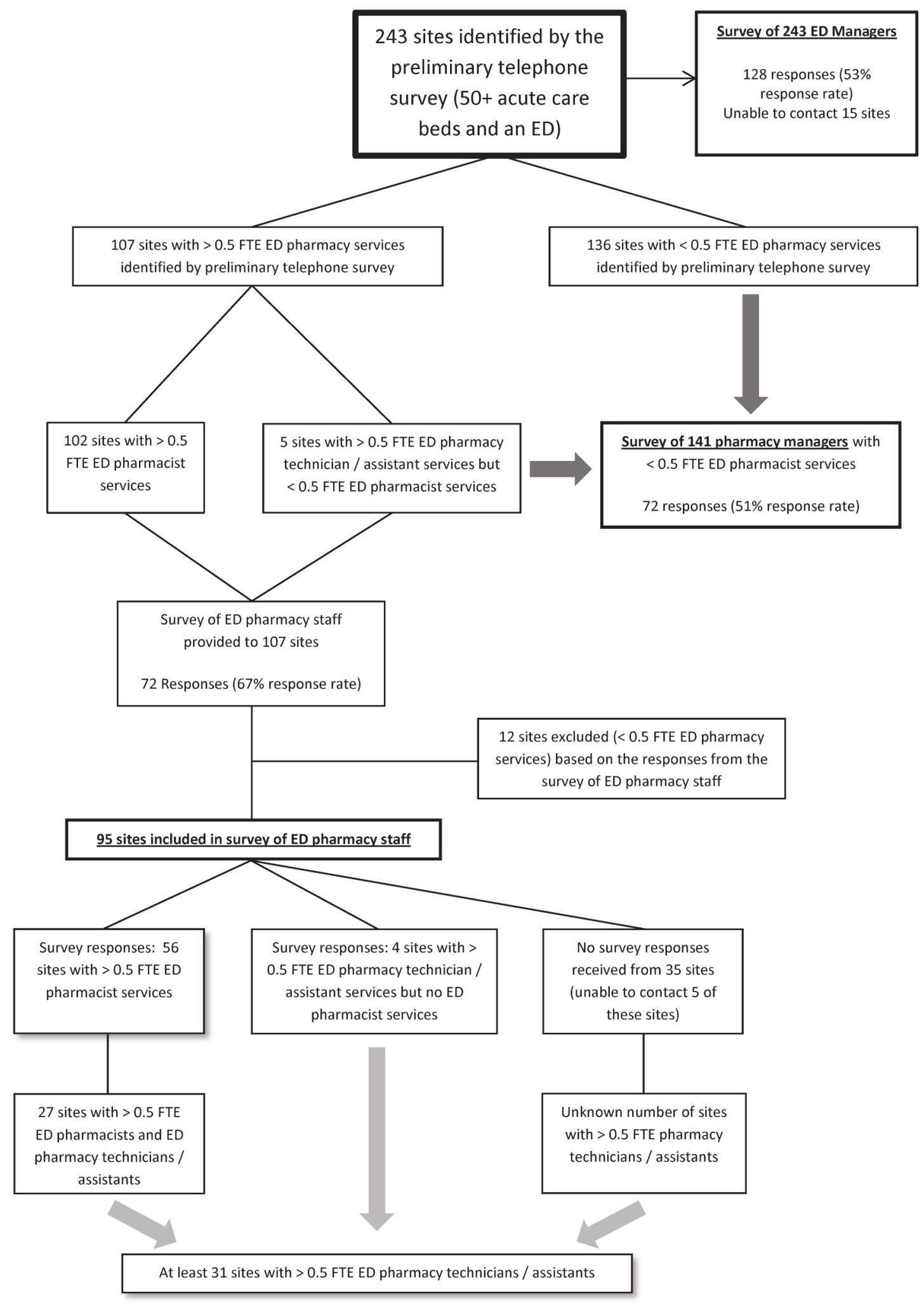

Figure 1. The distribution and response rates for a telephone survey and 3 electronic surveys targeting emergency department (ED) pharmacy teams, pharmacy managers, and ED managers. FTE = full-time equivalent. 
This single copy is for your personal, non-commercial use only.

For permission to reprint multiple copies or to order presentation-ready copies for distribution, contact CJHP at cjhpedit@cshp.ca

Table 2. Distribution of ED Pharmacist Responses and Description of Hospitals Surveyed

\begin{tabular}{|c|c|c|}
\hline Characteristic & $\begin{array}{l}\text { No. }(\%) \text { of } \\
\qquad(n=\end{array}$ & $\begin{array}{l}\text { Responses* } \\
\text { 56) }\end{array}$ \\
\hline Respondent's preferred lan & & \\
\hline English & 38 & (68) \\
\hline French & 18 & (32) \\
\hline Province or territory & & \\
\hline Yukon & 0 & $(0)$ \\
\hline Northwest Territories & 0 & $(0)$ \\
\hline Nunavut & 0 & (0) \\
\hline British Columbia & 5 & (9) \\
\hline Alberta & 4 & (7) \\
\hline Saskatchewan & 1 & (2) \\
\hline Manitoba & 7 & (13) \\
\hline Ontario & 15 & $(27)$ \\
\hline Quebec & 17 & (30) \\
\hline Newfoundland and Labrador & 0 & $(0)$ \\
\hline Nova Scotia & 2 & (4) \\
\hline New Brunswick & 4 & (7) \\
\hline Prince Edward Island & 0 & (0) \\
\hline Not specified & 1 & $(2)$ \\
\hline No. of ED visits/day & & \\
\hline $0-49$ & 8 & (14) \\
\hline 50-99 & 10 & (18) \\
\hline $100-149$ & 11 & (20) \\
\hline 150-199 & 20 & (36) \\
\hline$\geq 200$ & 5 & (9) \\
\hline Not specified & 2 & (4) \\
\hline No. of ED admissions/day & & \\
\hline $0-9$ & 7 & (13) \\
\hline 10-19 & 21 & (38) \\
\hline $20-29$ & 16 & (29) \\
\hline$\geq 30$ & 11 & (20) \\
\hline Not specified & 1 & $(2)$ \\
\hline
\end{tabular}

ED = emergency department.

*Percentages for some variables do not sum to exactly $100 \%$ because of rounding.

technicians but no pharmacists), representing up to $39 \%$ of all 243 hospitals screened. However, because of incomplete survey responses, the absolute number of ED pharmacy services in Canada could not be confirmed in this study. Formal survey responses confirmed and described 60 (63\%) of these 95 hospitals, 56 of which were from ED pharmacists. The geographic distribution and hospital-specific descriptors for these 56 ED pharmacist responses are presented in Table 2, with additional descriptive information below.

\section{Evolution of Clinical Pharmacy Services in the ED}

ED pharmacist services had been initiated in the 4 years preceding the survey in 24 (43\%) of the 56 hospitals, and only $11(20 \%)$ of the hospitals had started their ED pharmacist service 10 or more years ago. The ED fully funded the pharmacist positions at $8(14 \%)$ of the hospitals and partially funded a pharmacy position at only $1(2 \%)$ hospital. At all other hospitals, the ED pharmacy positions were funded by the hospital's pharmacy department. Among hospitals that already had 1 ED pharmacist, there were a total of at least 8 additional vacant ED pharmacist positions.

\section{ED Pharmacist Staffing and Hours of Service}

Overall, $54(96 \%)$ of the 56 ED pharmacist services reported providing morning through afternoon coverage. Six (11\%) and 2 (4\%) of 56 ED pharmacist services also reported providing evening and overnight coverage, respectively. Fortytwo $(75 \%)$ of the ED pharmacist services reported providing coverage Monday through Friday, and only 4 (7\%) of the EDs received additional weekend coverage. Thirty-eight of the hospitals (68\%) had 1 FTE pharmacist in the ED, and another $11(20 \%)$ had less than 1 FTE. Seventeen $(30 \%)$ of 56 ED pharmacists also covered clinical areas outside of the ED, and 5 (9\%) of 56 reported covering more than 1 ED.

Twenty-nine of the hospitals had multiple ED pharmacists; 22 of these hospitals rotated pharmacists through the ED assignment, and the other 7 hospitals had multiple pharmacists dedicated just to the ED. Of the 7 hospitals with more than 1 FTE pharmacist (13\% of the 56 hospitals with ED pharmacist staffing), 4 had extended hours of service and 2 also had ED pharmacy technicians.

\section{Services}

Table 3 shows the direct patient care activities performed by ED pharmacists. All medication orders were reviewed within $24 \mathrm{~h}$ for admitted and non-admitted patients in 44 (79\%) and $18(32 \%)$ of the 56 hospitals, respectively.

Respondents reported that, on average, ED pharmacists assessed between 11 and 15 patients each day, with priority given to those who were admitted or had pharmacy consult orders. A variety of other selection factors were used to prioritize patients, including specific diagnoses, age, renal function, target drugs, therapeutic levels, and information from patient rounds. Four of the ED pharmacists reported that their sites used a triage tool to prioritize patients; unfortunately, the survey did not solicit information about those tools.

Table 4 shows the indirect patient care activities performed by ED pharmacists, including formulary reviews, disaster preparedness, and research. Educating community care providers was an additional role recognized by survey respondents. Most of the ED pharmacist respondents (40 [71\%]) reported spending less than $25 \%$ of their time performing indirect patient care activities. ED pharmacists provided experiential education rotations in $38(70 \%)$ of 54 hospitals. Table 5 summarizes the number and distribution of these rotations. 
This single copy is for your personal, non-commercial use only.

For permission to reprint multiple copies or to order presentation-ready copies for distribution, contact CJHP at cjhpedit@cshp.ca

Table 3. Frequency of Direct Patient Care Activities* Performed by ED Pharmacists

Frequency; No. of Respondents

\begin{tabular}{|c|c|c|c|c|c|c|c|}
\hline Activity & NA & $\begin{array}{l}>\text { Once } \\
\text { per Day }\end{array}$ & Daily & Weekly & Infrequent & Never & $\begin{array}{c}\text { No } \\
\text { Response }\end{array}$ \\
\hline Order clarification & 0 & 46 & 8 & 0 & 1 & 0 & 1 \\
\hline Troubleshooting & 0 & 44 & 10 & 1 & 0 & 0 & 1 \\
\hline BPMH or medication reconciliation & 1 & 43 & 6 & 2 & 3 & 0 & 1 \\
\hline Renal assessment & 0 & 42 & 8 & 1 & 4 & 0 & 1 \\
\hline Allergy assessment & 0 & 36 & 12 & 4 & 2 & 0 & 2 \\
\hline Interaction assessment & 0 & 33 & 16 & 2 & 4 & 0 & 1 \\
\hline Drug information & 0 & 33 & 13 & 4 & 4 & 1 & 1 \\
\hline Screening for ADEs on admission & 1 & 28 & 14 & 2 & 5 & 4 & 2 \\
\hline Order verification & 4 & 28 & 4 & 3 & 13 & 2 & 2 \\
\hline Therapeutic monitoring & 0 & 24 & 21 & 6 & 4 & 0 & 1 \\
\hline Full pharmaceutical care work-ups & 0 & 21 & 15 & 9 & 10 & 0 & 1 \\
\hline Discharge counselling & 3 & 4 & 12 & 13 & 21 & 2 & 1 \\
\hline Reporting of medication error or ADE & 0 & 3 & 13 & 17 & 19 & 2 & 2 \\
\hline Trauma or "code blue" & 3 & 3 & 8 & 8 & 15 & 18 & 1 \\
\hline Medication preparation & 1 & 3 & 6 & 6 & 15 & 24 & 1 \\
\hline $\begin{array}{l}\text { Procedural sedation or } \\
\text { rapid-sequence intubation }\end{array}$ & 3 & 3 & 4 & 4 & 13 & 27 & 2 \\
\hline Outpatient antibiotic assessment & 6 & 3 & 4 & 2 & 13 & 27 & 1 \\
\hline $\begin{array}{l}\text { Postdischarge culture and } \\
\text { sensitivity assessment }\end{array}$ & 2 & 3 & 3 & 3 & 9 & 35 & 1 \\
\hline Toxicology review & 1 & 2 & 8 & 21 & 18 & 5 & 1 \\
\hline Deep vein thrombosis clinic & 5 & 2 & 1 & 11 & 17 & 19 & 1 \\
\hline $\begin{array}{l}\text { Administration of parenteral } \\
\text { medication }\end{array}$ & 2 & 1 & 1 & 3 & 4 & 44 & 1 \\
\hline ED rounds & 12 & 0 & 14 & 3 & 5 & 21 & 1 \\
\hline Other clinic & 12 & 0 & 2 & 1 & 6 & 33 & 2 \\
\hline $\begin{array}{l}\text { Administration of nonparenteral } \\
\text { medication }\end{array}$ & 2 & 0 & 1 & 3 & 6 & 43 & 1 \\
\hline
\end{tabular}

ADE = adverse drug event, $\mathrm{BPMH}=$ best possible medication history, $\mathrm{ED}=$ emergency department, NA = not applicable at respondent's hospital.

* Other activity identified in comments section of survey: identification of medications.

Table 4. Frequency of Indirect Patient Care Activities* Performed by ED Pharmacists

Frequency; No. of Respondents

\begin{tabular}{lcccccc}
\cline { 2 - 6 } Activity & $\begin{array}{c}\text { > Once } \\
\text { per Day }\end{array}$ & Daily & Weekly & Infrequent & Never & $\begin{array}{c}\text { No } \\
\text { Response }\end{array}$ \\
\hline Administration or management & 5 & 0 & 12 & 22 & 14 & 3 \\
Research & 4 & 4 & 7 & 19 & 19 & 3 \\
Education or in-service sessions & 3 & 3 & 17 & 28 & 3 & 2 \\
Formulary review & 3 & 0 & 3 & 38 & 10 & 2 \\
Drug utilization and drug shortages & 2 & 5 & 11 & 28 & 8 & 2 \\
Quality assurance & 2 & 2 & 18 & 28 & 4 & 2 \\
Committee work & 2 & 1 & 28 & 22 & 1 & 2 \\
Policy & 1 & 2 & 21 & 27 & 3 & 2 \\
Disaster preparedness & 1 & 0 & 1 & 37 & 15 & 2 \\
\hline
\end{tabular}

ED = emergency department.

*Other activity identified in comments section of the survey: education for community care providers. 
This single copy is for your personal, non-commercial use only.

For permission to reprint multiple copies or to order presentation-ready copies for distribution, contact CJHP at cjhpedit@cshp.ca

Table 5. Clinical Pharmacy Experiential Rotations in Emergency Medicine in Canadian Hospitals

\begin{tabular}{lrr} 
Variable & $\begin{array}{c}\text { No. (\%) of Hospitals } \\
(\boldsymbol{n}=\mathbf{5 6})\end{array}$ \\
\hline Type of rotations* & 34 & $(61)$ \\
Undergraduate & 5 & $(9)$ \\
Military & 26 & $(46)$ \\
Hospital residency & 10 & $(18)$ \\
PharmD & 1 & $(2)$ \\
Fellowship & & \\
\hline No. of rotations offered/yeart & 16 & $(29)$ \\
0 & 6 & $(11)$ \\
1 & 7 & $(13)$ \\
2 & 8 & $(14)$ \\
3 & 6 & $(11)$ \\
4 & 11 & $(20)$ \\
$\geq 5$ & 2 & $(4)$ \\
Unknown & &
\end{tabular}

\begin{tabular}{lrr}
\hline Regional distribution of rotations & & \\
Residency & 9 & $(35)$ \\
Quebec & 7 & $(27)$ \\
Ontario & 5 & $(19)$ \\
British Columbia & 2 & $(8)$ \\
New Brunswick & 1 & $(4)$ \\
Alberta & 1 & $(4)$ \\
Manitoba & 1 & $(4)$ \\
Nova Scotia & & \\
\hline PharmD & 4 & $(40)$ \\
British Columbia & 4 & $(40)$ \\
Ontario & 1 & $(10)$ \\
New Brunswick & 1 & $(10)$ \\
Manitoba & & \\
\hline Fellowship & 1 & $(100)$ \\
Quebec &
\end{tabular}

*Some institutions had more than one type of experiential rotation.

+Percentages for this variable do not sum to exactly $100 \%$ because of rounding.

Respondents from 4 of the 7 hospitals with multiple ED pharmacists reported that members of the ED pharmacy team completed best possible medication histories (BPMHs) for the majority of admitted patients in the ED. A more detailed description of medication reconciliation activities in Canadian EDs, including that of a hospital that offers 24 -h service 7 days each week, is published elsewhere in this issue. ${ }^{53}$

\section{Training}

A hospital residency was the most common level of training for ED pharmacists, but 14 (25\%) of the ED pharmacists had no additional training beyond the entry-level pharmacist degree. ED pharmacists' training and education is described in more detail in Table 6. Of the $34 \mathrm{ED}$ pharmacists who reported performing trauma or resuscitation care, only $17(50 \%)$ reported having Advanced Cardiac Life Support (ACLS) training and only 5
(15\%) reported having Pediatric Advanced Life Support (PALS) training, whereas 21 (62\%) reported having basic cardiopulmonary resuscitation training. Nine of the $10 \mathrm{ED}$ pharmacists who reported administering parenteral medications were ACLStrained, but only 1 of these 10 pharmacists had received training for peripheral IV starts.

\section{Communication}

A designated workspace was provided for the ED pharmacist at $35(63 \%)$ of the 56 hospitals, and ED pharmacists were primarily contacted by pager (42 [75\%]), cell phone (17 [30\%]), or a commercial communication system (Vocera, San Jose, California) (12 [21\%]). Overhead paging and face-to-face communications were reported to be a major form of initial contact at only 5 hospitals (9\%) each.

\section{Pharmacy Technicians}

ED pharmacy technician services were offered in at least 31 hospitals in Canada (Figure 1), 16 (52\%) of which were in Quebec. The presence of an ED pharmacy technician was most common in hospitals with more than $10 \mathrm{ED}$ hospital admissions per day. The most common role of the ED pharmacy technician, collecting BPMHs, occurred at $27(87 \%)$ of the 31 sites. Other activities commonly performed by ED pharmacy technicians included maintaining wardstock, entering medication orders, and delivering "stat" medications. Most of these technician services were provided by only 1 FTE or less, with 5 days per week daytime coverage. Eleven hospitals had more than $1 \mathrm{ED}$ pharmacy technician, and most of these had expanded hours of service, including evening and weekend coverage.

\section{Survey of Pharmacy Managers}

Survey responses from 72 hospital-specific pharmacy managers at institutions without ED pharmacists were received primarily from Ontario (24), Quebec (17), and British Columbia (12). The overall response rate for this survey was $51 \%(72 / 141)$. Fifty-eight (81\%) of these managers reported the need for an ED pharmacist service, and 36 (50\%) had received a request for an ED pharmacist from an ED manager. Respondents from 18 hospitals reported having a vacant ED pharmacist position $(n=13)$ and/or actively seeking funding for an ED pharmacist position $(n=9)$. Pharmacy managers largely defined the need to provide clinical pharmacy services in the ED as having either equal $(n=35 / 72[49 \%])$ or higher $(n=33 / 72[46 \%])$ priority relative to other ward services. Only 4 hospitals reported the role of an ED pharmacist as being less of a priority relative to other patient care areas.

Pharmacy managers reported that the main barriers to initiating an ED pharmacist service were no funding (49 [68\%]), competing priorities (36 [50\%]), and a lack of trained staff (31 
This single copy is for your personal, non-commercial use only.

For permission to reprint multiple copies or to order presentation-ready copies for distribution, contact CJHP at cjhpedit@cshp.ca

Table 6. Level of Training and Education of ED Pharmacists

\begin{tabular}{lrrrr} 
& \multicolumn{5}{c}{ Category; No. (\%) of Hospitals* } \\
\cline { 2 - 6 } Training or Education & \multicolumn{3}{c}{ Most Trained $(\boldsymbol{n}=\mathbf{5 6})$} & Least Trained $(\boldsymbol{n}=\mathbf{2 9})$ \\
\hline Highest level of education & 14 & $(25)$ & 7 & $(24)$ \\
Entry-level & 5 & $(9)$ & 2 & $(7)$ \\
"In-house" ED training & 27 & $(48)$ & 16 & $(55)$ \\
Hospital residency & 9 & $(16)$ & 0 & $(0)$ \\
Postgraduate PharmD & 1 & $(2)$ & 0 & $(0)$ \\
ED residency or fellowship & 0 & $(0)$ & 4 & $(14)$ \\
Unknown & 30 & $(54)$ & 8 & $(28)$ \\
Certification & 17 & $(30)$ & 2 & $(7)$ \\
Cardiopulmonary resuscitation (CPR) & 5 & $(9)$ & 0 & $(0)$ \\
Advanced Cardiac Life Support (ACLS) & 4 & $(7)$ & 0 & $(0)$ \\
Pediatric Advanced Life Support (PALS) & 2 & $(4)$ & 1 & $(3)$ \\
Advanced Hazmat Life Support (AHLS) & 2 & $(4)$ & 0 & $(0)$ \\
Advanced Trauma Life Support (ATLS) & & & & \\
Peripheral IV starts & & & &
\end{tabular}

$\mathrm{ED}=$ emergency department.

*For sites with multiple ED pharmacists, the level of training and education is described for the most-trained and the least-trained ED pharmacist. For hospitals with one ED pharmacist, the level of training and education is documented in the "most-trained" category (i.e., "least trained" was documented only for hospitals with more than one ED pharmacist).

[43\%]). About half (37 [51\%]) of the pharmacy managers considered an entry-level pharmacy degree to be adequate training for an ED pharmacist, whereas 28 (39\%) would require that ED pharmacists complete a hospital residency and $4(6 \%)$ required a graduate Doctor of Pharmacy degree. Lack of interest from staff (6 [8\%]) and lack of space in the ED (1 [1\%]) were not major barriers identified in this survey.

Pharmacy managers at $42(58 \%)$ of the 72 hospitals reported that they would support an ED pharmacist administering parenteral medications to patients if adequately trained to do so. However, these respondents reported that they would place restrictions on this practice, such that pharmacist practice would be similar to $(19$ [45\%]) or more limited than (12 [29\%]) nursing practice in most institutions; however, 6 (14\%) would allow ED pharmacists to administer medications that nurses are not authorized to administer, albeit only if a physician were present.

\section{Survey of ED Managers}

Survey responses were received from 128 (53\%) of 243 ED managers, representing almost all regions of Canada. All but 2 (2\%) of the ED managers were aware of the presence or absence of ED pharmacy services at their hospitals. Sixty (47\%) of the 128 respondents reported having an ED with dedicated pharmacy services. An ED pharmacist was considered a valuable team member by 57 (95\%) of these ED managers.

All of the $66 \mathrm{ED}$ managers whose hospitals did not have dedicated pharmacy services reported that they would value a traditional pharmacist role that included conducting medication reconciliation, identifying and resolving medication-related issues, ensuring rapid delivery of medications, answering drug information questions, counselling patients, and providing in-service education. Forty-six (70\%) of these ED managers would support having an ED pharmacist assist with the preparation and/or administration of medications to high-risk patients (e.g., cases of trauma, cardiac arrest, sepsis, stroke, toxicity, intubation, and procedural sedation). Only $6(9 \%)$ opposed ED pharmacists assisting in this manner.

\section{DISCUSSION}

There is no agreement in the literature on what constitutes an acceptable survey response rate, but the response rates for the 3 surveys in this study fell within the range of various minimally acceptable response rates that have been reported previously (50\% to $75 \%) .{ }^{54}$ Conducting this study during the summer months and not providing compensation or incentives may have adversely affected the response rates.

This study identified a greater presence of ED pharmacy services in Canada than previous US data but a lower percentage than presented in the Hospital Pharmacy in Canada 2011/2012 Report. The current study's more stringent definition of dedicated ED pharmacy services may explain the latter difference. ${ }^{25,49-51}$ Similar to previously published data ${ }^{49-51} \mathrm{ED}$ pharmacist services in Canada were more common in larger hospitals. ED pharmacy services may exist in hospitals with fewer than 50 acute care beds, despite exclusion of these smaller hospitals from the current study. The most recent US survey ${ }^{50}$ reported that $4.3 \%$ of US hospitals with fewer than 50 acute care beds had pharmacists assigned to the ED; however, the results from that survey were not available at the time the current Canadian survey was undertaken. 
The establishment of ED pharmacist services in the large majority of Canadian hospitals is relatively new, and the need to provide such services has become a high priority in many hospitals. More than $80 \%$ of pharmacy managers and all ED managers indicated a desire to initiate ED pharmacy services where such services did not yet exist, although this result may have been affected by selection bias, given that the cover letter disclosed that the survey was being conducted by pharmacists. Given that current ED pharmacists are able to assess only a small number of patients each week, a case could be made for expanding pharmacist services at sites with such services already in place. Further interest in the provision or expansion of ED pharmacist services was objectively supported by the 21 hospitals that had a vacant ED pharmacist position (8 of which had existing ED pharmacy services and an additional 13 that did not have existing ED pharmacy services).

The majority of ED pharmacists in Canada were reported to perform most of the 7 pharmacy activities associated with reductions in patient mortality rates. Medication reconciliation is one of the most common activities performed, and a more comprehensive assessment of this role for the pharmacy team in Canadian EDs is described elsewhere in this issue. ${ }^{53}$ This survey did not specifically assess drug protocol development as a role, although almost all ED pharmacists are involved with committees, policy development, and quality assurance projects. Participation in resuscitation efforts and involvement in patient care rounds, where applicable, were 2 possible areas for improvement.

Screening for ADEs is one of the most common services provided by Canadian ED pharmacists. Clinical decision rules have been established to screen for possible ADEs in ED patients, but this tool requires prospective validation. ${ }^{55}$ The current Canadian survey study identified 4 hospitals that were using a triage tool to identify patients who would receive pharmaceutical care work-ups. Understanding these processes is an area for future study.

The CSHP 2015 initiative set expectations that pharmacists review all ED medication orders within $24 \mathrm{~h},{ }^{47}$ but the Hospital Pharmacy in Canada 2011/2012 Report suggested that this was occurring in only $29 \%$ of hospitals..$^{56}$ Although these survey responses suggest a greater challenge in meeting the goal for non-admitted patients, 12 (21\%) of the 56 responses from ED pharmacists indicated that hospitals were also challenged to meet this goal for admitted patients. Given the high patient volumes in the ED, the short duration of stay for ED outpatients, and the lack of around-the-clock ED pharmacist services, meeting this CSHP 2015 expectation for ED outpatients remains a considerable challenge.

CSHP 2015 objective 6.4 suggests the need for pharmacy departments to have emergency preparedness strategies in place. ${ }^{47}$ Given their understanding of how both pharmacies and EDs operate, ED pharmacists should ideally be involved with this planning. This survey revealed that relatively few hospitals in Canada had incorporated an ED pharmacist into disaster preparedness planning activities.

Since the 1970s, pharmacists have participated in resuscitation teams. ${ }^{13,14}$ This service has been associated with reduced mortality and increased compliance with ACLS guidelines. ${ }^{7}$ Despite that evidence, most pharmacists who work in clinical areas do not participate in resuscitation teams. The survey results reported here indicate that the majority of ED pharmacists are members of resuscitation teams, but almost half of these pharmacists infrequently perform this role. Although detailed descriptions of specific activities performed during resuscitation were not obtained, it was disconcerting that many ED pharmacists had not completed ACLS and PALS training and that 26 (46\%) of the 56 sites with ED pharmacy services did not even have an ED pharmacist who had completed basic cardiopulmonary resuscitation training. All ED pharmacists that reported having ACLS training were actively involved as members of a resuscitation team.

Assistance with procedural sedation and rapid-sequence intubation is well described in the literature as an opportunity for pharmacists to enhance medication safety practices in high-risk cases. ${ }^{10-12,57}$ With less than one-third of ED pharmacists actively involved in these activities, training curricula should be expanded to further support this role. The development of guidelines for practice for Canadian $\mathrm{ED}$ pharmacists, including training requirements for specific activities, may assist pharmacists and pharmacy managers in developing these roles further.

Specific training for administering parenteral medications was not assessed in the current survey. However, almost all ED pharmacists who reported administering such medications were ACLS-trained, and only 1 pharmacist had received training for peripheral IV starts. Over half of pharmacy managers would support this role with appropriate training, and of these, most would limit the role to equal to or less than a nurse's scope. In addition to receiving appropriate training to administer parenteral medications, ED pharmacists should receive regulatory and hospital-specific permission before providing this service to patients. Canadian guidelines and training requirements for this practice would also provide support for expanding this role.

A lack of clinical pharmacy residency training rotations in EDs has been identified in the United States, ${ }^{25,58}$ and the Canadian results reported here support this concern. About half of hospitals reported offering a residency rotation in emergency medicine, and less than a quarter offered a PharmD or fellowship rotation in the ED. This situation also reflects the training of current ED pharmacists. Canadian pharmacy managers indicated that a lack of appropriate training was a barrier to providing ED pharmacist services. This result emphasizes the need to increase the number of advanced emergency medicine rotations available in hospital pharmacy training curricula. Given that British 
Columbia has 1 of 2 postgraduate PharmD programs in Canada, it is no surprise that 4 of the 5 pharmacy managers (from hospitals without ED pharmacy services) requiring a PharmD for this role were from $\mathrm{BC}$ hospitals. This may be a disproportionate barrier in British Columbia, leading to the indication, in the Hospital Pharmacy in Canada 2011/2012 Report, that this province has a lower rate of $\mathrm{ED}$ pharmacist assignment than other regions in Canada. ${ }^{51}$

This study did not identify when the provision of ED pharmacy technician services had commenced, but at least one-third of ED pharmacy services included pharmacy technicians. It was not possible to estimate the presence of ED pharmacy technician services for the 35 hospitals that did not respond to the ED pharmacy team survey, because the presence of ED pharmacy technicians was not ascertained during preliminary telephone screening.

\section{CONCLUSIONS}

Overall, these survey results suggest that ED pharmacy services are relatively new and rapidly evolving in Canadian hospitals. Expansion of clinical experiential training opportunities in emergency medicine is needed to support further growth in both the role provided and the number of hospitals where this service is available. Given the number of ED patients seen each day and the current barriers to providing additional ED pharmacist services, future research is needed to identify key performance indicators and required training for efficient use of ED pharmacist resources. There is also a need to identify strategies for developing business cases to add more ED pharmacists and technicians at Canadian hospitals.

\section{References}

1. Bond CA, Raehl CL. Clinical pharmacy services, pharmacy staffing, and hospital mortality rates. Pharmacotherapy. 2007;27(4):481-93.

2. Kaboli PJ, Hoth AB, McClimon BJ, Schnipper JL. Clinical pharmacists and inpatient medical care: a systematic review. Arch Intern Med. 2006;166(9):955-64.

3. Gillespie U, Alassaad A, Henrohn D, Garmo H, Hammarlund-Udenaes $\mathrm{M}$, Toss $\mathrm{H}$, et al. A comprehensive pharmacist intervention to reduce morbidity in patients 80 years or older. Arch Intern Med. 2009;169(9):894-900.

4. Makowsky MJ, Koshman SL, Midodzi WK, Tsuyuki RT. Capturing outcomes of clinical activities performed by a rounding pharmacist practicing in a team environment (the COLLABORATE Study). Med Care. 2009; $47(6): 642-50$.

5. Chisholm-Burns MA, Lee JK, Spivey CA, Slack M, Herrier RN, HallLipsey E, et al. US pharmacists' effect as team members on patient care: systematic review and meta-analyses. Med Care. 2010;48(10):923-33.

6. Scarponcini TR, Edwards CJ, Rudis MI, Jasiak KD, Hays DP. The role of the emergency pharmacist in trauma resuscitation. J Pharm Pract. 2011; 24(2):146-59.

7. Hashemipour Z, Delgado G, Dehoorne-Smith M, Edwin SB. Pharmacist integration into cardiac arrest response teams. Am J Health Syst Pharm. 2013;70(8):662,664,666-7.

8. Patanwala AE, Thomas MC, Casanova TJ, Thomas R. Pharmacists' role in procedural sedation and analgesia in the emergency department. Am J Health Syst Pharm. 2012;69(15):1336-42.

9. Acquisto NM, Baker SN. Antimicrobial stewardship in the emergency department. J Pharm Pract. 2011;24(2):196-202.

10. Baker SN, Weant KA. Procedural sedation and analgesia in the emergency department. J Pharm Pract. 2011;24(2):189-95.

11. Grindrod KA, Taddei A. The role of the pharmacist in procedural sedation and analgesia in the emergency department. Can J Hosp Pharm. 2008;61(1):49-54.

12. Hampton, JP. Rapid-sequence intubation and the role of the emergency department pharmacist. Am J Health Syst Pharm. 2011;68(14):1320-30.

13. Schwerman E, Schwartau N, Thompson CO. The pharmacist as a member of the cardiopulmonary resuscitation team. Drug Intell Clin Pharm. 1973;7:299-309.

14. Elenbaas R. Pharmacist on resuscitation team. N Engl J Med. 1972; 287(3):151.

15. Levy DB. Documentation of clinical and cost-saving pharmacy interventions in the emergency room. Hosp Pharm. 1993;28(7):624-7,630-4,653.

16. Lada P, Delgado G Jr. Documentation of pharmacists' interventions in an emergency department and associated cost avoidance. Am J Health Syst Pharm. 2007;64(1):63-8.

17. Fairbanks RJ, Hildebrand JM, Kolstee KE, Schneider SM, Shah MN. Medical and nursing staff highly value clinical pharmacists in the emergency department. Emerg Med J. 2007;24(1):716-8.

18. Wanbon R. Clinical pharmacy services in emerg. The role of a clinical pharmacist in the emergency department. Can Healthc Netw [serial on Internet, published by Rogers Media Inc]. 2012 Nov 27 [cited 2013 Oct 19]. Available from: www.canadianhealthcarenetwork.ca/pharmacists/clinical/ clinical-pharmacy-services-in-emerg-18486. Registration required to access content.

19. Wymore ES, Casanova TJ, Broekemeirer RL, Martin JK Jr. Clinical pharmacist's daily role in the emergency department of a community hospital. Am J Health Syst Pharm. 2008;65(5):395-6,398-9.

20. Fairbanks RJ, Hays DP, Webster DF, Spillane LL. Clinical pharmacy services in an emergency department. Am J Health Syst Pharm. 2004;61(9):934-7.

21. Rudis MI, Attwood RJ. Emergency medicine pharmacy practice. J Pharm Pract. 2001;24(2):135-45.

22. Hughes DW, Roth JM, Laurel Y. Establishing emergency department pharmacy services. Am J Health Syst Pharm. 2010;67(13):1053-7.

23. Cohen V, Jellinek SP, Hatch A, Motov S. Effect of clinical pharmacists on care in the emergency department: a systematic review. Am J Health Syst Pharm. 2009;66(15):1353-61.

24. Ammons DK, Roberts N. Prioritizing pharmacy services in the emergency department. Am J Health Syst Pharm. 1997;54(15):1702-5.

25. Thomasset KB, Faris R. Survey of pharmacy services provision in the emergency department. Am J Health Syst Pharm. 2003;60(15):1561-4.

26. Randolph TC. Expansion of pharmacists' responsibilities in an emergency department. Am J Health Syst Pharm. 2009;66(16):1484-7.

27. Ling JM, Mike LA, Rubin J, Abraham P, Howe A, Patka J, et al. Documentation of pharmacist interventions in the emergency department. Am J Health Syst Pharm. 2005;62(17):1793-7.

28. Emergency Pharmacist Research Team. The emergency pharmacist (EPh): a safety measure in emergency medicine. Part II: Role of the EPh [slide presentation]. Rochester (MN): University of Rochester, Department of Emergency Medicine; [cited 2012 Jun 23]. Available from: www.emergency pharmacist.org/doc/toolkit $\% 20$ page/Powerpoint $\% 20$ tools/ 2-EPh\%20role.pdf

29. Fairbanks RJ. The optimized emergency pharmacist role [slide presentation]. AHRQ Patient Safety and HIT Conference; 2006 Jun 5 [cited 2012 Jun 23]; Washington (DC). Available from: www.emergencypharmacist.org/ doc/AHRQ_PS_HIT_EDP.pdf.

30. Hays DP. Clinical pharmacy services in the emergency department [slide presentation]. AHRQ Conference; 2007 Sep 27 [cited 2012 Jun 23]; Bethesda (MD). Available from: www.emergencypharmacist.org/doc/ Resource\%20Documents/Hays_AHRQ2007.pdf

31. American Society of Health-System Pharmacists. ASHP statement on pharmacy services to the emergency department. Am J Health Syst Pharm. 2008;65(24):2380-3.

32. Eppert HD, Reznek AJ; American Society of Health-System Pharmacists. ASHP guidelines on emergency medicine pharmacist services. Am J Health Syst Pharm. 2011;68(23):e81-95.

33. Zed PJ, Abu-Laban RB, Balen RM, Loewen PS, Hohl CM, Brubacher JR, et al. Incidence, severity and preventability of medication-related visits to the emergency department: a prospective study. CMAJ. 2008;178(12):1563-9.

34. Patel P, Zed PJ. Drug-related visits to the emergency department: how big is the problem? Pharmacotherapy. 2002;22(7):915-23.

35. Aminzadeh F, Dalziel WB. Older adults in the emergency department: a systematic review of patterns of use, adverse outcomes, and effectiveness of interventions. Ann Emerg Med. 2002;39(3):238-47.

36. Bates DW, Cullen DJ, Laird N, Petersen LA, Small SD, Servi D, et al. Incidence of adverse drug events and potential adverse drug events. Implications for prevention. ADE Prevention Study Group. JAMA. 
This single copy is for your personal, non-commercial use only.

For permission to reprint multiple copies or to order presentation-ready copies for distribution, contact CJHP at cjhpedit@cshp.ca

1995;274(1):29-34

37. Hohl CM, Nosyk B, Kuramoto L, Zed PJ, Brubacher JR, Abu-Laban RB, et al. Outcomes of emergency department patients presenting with adverse drug events. Ann Emerg Med. 2011;58(3):270-279.e4.

38. Samoy LJ, Zed PJ, Wilbur K, Balen RM, Abu-Laban RB, Roberts M. Drug-related hospitalizations in a tertiary care internal medicine service of a Canadian hospital: a prospective study. Pharmacotherapy. 2006: 26(11):1578-86.

39. Zed PJ. Drug-related visits to the emergency department. J Pharm Pract. 2005; 18:329-35.

40. Hafner JW, Belknap SM, Squillante MD, Bucheit KA. Adverse drug events in emergency department patients. Ann Emerg Med. 2002;39(3):258-67.

41. Baena MI, Faus MJ, Fajardo PC, Luque FM, Sierra F, Martinez-Olmos J, et al. Medicine-related problems resulting in emergency department visits. Eur J Clin Pharmacol. 2006;62(5):387-93.

42. Zed PJ. Identification and classification of drug-related problems in the emergency department [abstract]. CJEM. 2007;9:187.

43. Forster AJ, Rose NG, Van Walraven C, Stiell I. Adverse events following an emergency department visit. Qual Saf Health Care. 2007;16(1):17-22.

44. Schnipper JL, Kirwin JL, Cotugno MC, Wahlstrom SA, Brown BA, Tarvin $\mathrm{E}$, et al. Role of pharmacist counseling in preventing adverse drug events after hospitalization. Arch Intern Med. 2006;166(5):565-71.

45. Cesarz JL, Steffenhagen AL, Svenson J, Hamedani AG. Emergency department discharge prescription interventions by emergency medicine pharmacists. Ann Emerg Med. 2013;61(2):209-214.e1.

46. Emergency department. In: Qmentum program standards. Version 9. Ottawa (ON): Accreditation Canada; 2014.

47. Canadian hospital pharmacy 2015 (CSHP 2015). Ottawa (ON): Canadian Society of Hospital Pharmacists; 2008 [cited 2014 Feb 25]. Available from: www.cshp.ca/dms/dmsView/2_CSHP-2015-Goals-and-ObjectivesFeb-25\%2707-w-Appdx-rev-May\%2708.pdf

48. Pedersen CA, Scheider PJ, Scheckelhoff DJ. ASHP national survey of pharmacy practice in hospital settings: dispensing and administration2005. Am J Health Syst Pharm. 2006;63(4):327-45.

49. Pedersen CA, Schneider PJ, Scheckelhoff DJ. ASHP national survey of pharmacy practice in hospital settings: dispensing and administration2008. Am J Health Syst Pharm. 2009;66(10):926-46.

50. Pedersen CA, Schneider PJ, Scheckelhoff DJ. ASHP national survey of pharmacy practice in hospital settings: monitoring and patient education2012. Am J Health Syst Pharm. 2013;70(9):787-803.

51. Bussières JF. Chapter B: Clinical pharmacy services. In: Babich M, Bornstein C, Bussières JF, Doucette D, Hall KW, Lefebvre P, et al., editors. Hospital pharmacy in Canada 2011/2012 report. Eli Lilly Canada Inc; 2013 [cited 2014 Feb 17]. p. 3-16. Available from: www.lillyhospitalsurvey.ca/hpc2/ content/2012_report/chapter_b\%20.pdf

52. Committee on the Future of Emergency Care in the United States Health System; Board on Health Care Services; Institute of Medicine. Hospitalbased emergency care: at the breaking point. Washington (DC): National Academies Press; 2006.

53. Wanbon R, Lyder C, Villeneuve E, Shalansky S, Manuel L, Harding M. Medication reconciliation practices in Canadian emergency departments: a national survey. Can J Hosp Pharm. 2015;69(3):202-9.

54. Draugalis JR, Coons SJ, Plaza CM. Best practices for survey research reports: a synopsis for authors and reviewers. Am J Pharm Educ. 2008;72(1): Article 11.

55. Hohl CM, Yu E, Hunte GS, Brubacher JR, Hosseini F, Argent CP, et al. Clinical decision rules to improve the detection of adverse drug events in emergency department patients. Acad Emerg Med. 2012;9:640-9.
56. Bornstein C. Chapter G: CSHP 2015. In: Babich M, Bornstein C, Bussières JF, Doucette D, Hall KW, Lefebvre P, et al., editors. Hospital pharmacy in Canada 2011/2012 report. Eli Lilly Canada Inc; 2013 [cited 2014 Feb 17]. p. 53-64. Available from: www.lillyhospitalsurvey.ca/hpc2/content/2012_ report/chapter_g\%20.pdf

57. Patanwala AE, Sanders AB, Thomas MC, Acquisto NM, Weant KA, Baker $\mathrm{SN}$, et al. A prospective, multicenter study of pharmacist activities resulting in medication error interception in the emergency department. Ann Emerg Med. 2012;59(5):369-73.

58. Idrees U, Clements E. The state of U.S. emergency care: a call to action for hospital pharmacists. Ann Pharmacother. 2006;40(12):2251-3.

Richard Wanbon, BSc, BSc(Pharm), ACPR, PharmD, is a Clinical Pharmacy Specialist (Emergency Medicine), Pharmacy Department, Royal Jubilee Hospital, Island Health Authority, Victoria, British Columbia.

Catherine Lyder, BSc(Pharm), MHSA, is Coordinator of Professional and Membership Affairs, Canadian Society of Hospital Pharmacists, Ottawa, Ontario.

Eric Villeneuve, BPharm, MSc, PharmD, is a Clinical Pharmacist (Emergency Medicine), Pharmacy Department, McGill University Health Centre, Montreal, Quebec.

Stephen Shalansky, BSC(Pharm), ACPR, PharmD, FCSHP, is Clinical Coordinator, Pharmacy Department, Providence Healthcare, Lower Mainland Pharmacy Services, Vancouver, British Columbia. He is also a Clinical Professor with the Faculty of Pharmaceutical Sciences, The University of British Columbia, Vancouver, British Columbia.

Leslie Manuel, BSC, BSC(Pharm), ACPR, PharmD, is Pharmacy Clinical Manager and Clinical Pharmacist (Emergency Medicine), Pharmacy Department, The Moncton Hospital, Horizon Health Network, Moncton, New Brunswick.

Melanie Harding, BSP, ACPR, is a Clinical Pharmacist with the Emergency and Home Parenteral Therapy Program, Pharmacy Department, South Health Campus, Alberta Health Services, Calgary, Alberta.

Competing interests: None declared.

\section{Address correspondence to:}

Dr Richard Wanbon

Royal Jubilee Hospital - Pharmacy Administration

1952 Bay Street

Victoria BC V8R 1J8

e-mail: Richard.Wanbon@viha.ca

Acknowledgements: The authors would like to thank Patrick Falkiner, Camille Petit, James Nataraj, and Erin Dunn for their assistance with identifying survey recipients; Heather Goodland for her contributions to the survey assessment; and Paul Murgoi for his verification of the French translation of study materials. This research group was formed within the Canadian Society of Hospital Pharmacists' Emergency Medicine Pharmacy Specialty Network.

Funding: None received. 